\title{
Aplicação foliar de extrato de alga na cultura da batata
}

\section{Clarice Backes ${ }^{1}$, Roberto Lyra Villas Bôas ${ }^{2}$, Alessandro José Marques Santos ${ }^{1}$, Adriana Aparecida Ribon ${ }^{3}$, Diógenes Martins Bardiviesso ${ }^{4}$}

\author{
${ }^{1}$ Universidade Estadual de Goiás - UEG, Campus de São Luís de Montes Belos, São Luís de Montes Belos, Goiás, Brasil. E-mail: \\ clarice.backes@ueg.br, alessandro.santos@ueg.br \\ ${ }^{2}$ Universidade Estadual Paulista "Júlio de Mesquita Filho" - UNESP, Faculdade de Ciências Agronômicas de Botucatu, Botucatu, \\ São Paulo, Brasil. E-mail: rlvboas@fca.unesp.br \\ ${ }^{3}$ Universidade Estadual de Goiás - UEG, Campus de Palmeiras de Goiás, Palmeiras de Goiás, Goiás, Brasil. E-mail: \\ adriana.ribon@ueg.br \\ ${ }^{4}$ Universidade Estadual de Mato Grosso do Sul - UEMS, Unidade Universitária de Cassilândia, Cassilândia, Mato Grosso do Sul, \\ Brasil. E-mail: bardiviesso@uems.br
}

Recebido: 20/03/2017; Aceito: 03/07/2017

\section{RESUMO}

No presente trabalho, objetivou-se avaliar os efeitos da aplicação foliar do extrato da alga Ascophyllum nodosum no crescimento e produtividade da cultura da batata. $O$ experimento foi conduzido dentro de uma área de plantio comercial de batata no município de Itapetininga-SP. Utilizou-se a variedade Asterix, em um delineamento de blocos ao acaso, com cinco tratamentos e cinco repetições. Os tratamentos foram constituídos de cinco doses de extrato de alga Ascophyllun nodosum, $0 ; 0,5 ; 1 ; 2 ; \mathrm{e} 4 \mathrm{~L} \mathrm{ha}^{-1}$, aplicado às plantas via foliar. Ao longo do ciclo foram avaliadas as variáveis: altura da planta; número de hastes por planta; intensidade de coloração verde da folha (ICV); concentração de nutrientes nas folhas e área foliar da quarta folha. Ao final quantificou-se o número de tubérculos por planta, a produtividade total e comercial das batatas. As soluções contendo extrato de algas promoveram maior crescimento das plantas. A solução contendo $4 \mathrm{~L} \mathrm{ha}^{-1}$ de extrato de alga proporcionou a produção de tubérculos de maior diâmetro e a maior produtividade.

Palavras-chave: Solanum tuberosum, bioestimulante, Ascophyllum nodosum

\section{Foliar application of seaweed extract in potato culture}

\section{ABSTRACT}

In the present work, the objective of this study was to evaluate the effects of foliar application of Ascophyllum nodosum extract on growth and yield of potato crop. The experiment was conducted inside a commercial potato planting area in the municipality of Itapetininga-SP. The variety Asterix was used in a randomized block design with five treatments and five replicates. The treatments consisted of five doses of seaweed extract Ascophyllun nodosum, $0 ; 0.5 ; 1 ; 2$; and $4 \mathrm{~L} \mathrm{ha}^{-1}$, applied to the plants via leaf. During the cycle, the following variables were evaluated: Plant height; Number of stems per plant; intensity of coloration leaf green (ICV); Concentration of nutrients in the leaves and leaf area of the fourth leaf. At the end, the number of tubers per plant was quantified, the total and commercial productivity of the potatoes. Solutions containing algae extract promoted higher plant growth. The solution containing $4 \mathrm{~L} \mathrm{ha}^{-1}$ of seaweed extract provided the production of tubers of larger diameter and higher productivity

Key words: Solanum tuberosum, bio-stimulant, Ascophyllum nodosum. 


\section{Introdução}

Nos últimos anos, a agricultura tem apresentado ganhos expressivos quanto à produtividade graças ao emprego de tecnologias. Na cultura da batata, esse aumento de produtividade deve-se principalmente ao uso de cultivares adaptadas, aplicação adequada de fertilizantes e corretivos e controle eficiente de pragas e doenças.

A adoção de produtos com ação bioestimulante também pode promover ganhos no cultivo de batata. De acordo com Silva et al. (2008), os produtos bioestimulantes apresentam concentração e proporção de componentes que contribuem para o incremento do desenvolvimento vegetal e da produtividade.

$\mathrm{O}$ extrato da alga Ascophyllum nodosum tem sido utilizado em diversas culturas, devido à sua ação bioestimulante. Quando aplicado nas plantas o extrato de algas proporciona maior resistência ao estresse, em função da presença de betaína em seu conteúdo (FERNANDES; SILVA, 2011). Devido à concentração considerável de auxinas, giberelinas e citocininas, a aplicação do extrato de alga promove o aumento do crescimento e da frutificação (FERNANDES; SILVA, 2011). O seu uso é frequente na Europa, sendo aplicado via foliar ou via solo tanto na agricultura convencional como na orgânica (MASNY et al., 2004).

Mógor et al. (2008) estudando o efeito da aplicação foliar de extrato de alga, ácido l-glutâmico e cálcio em feijoeiro identificaram o efeito dos tratamentos no crescimento inicial, ao longo do ciclo das plantas e na produção de grãos, caracterizando o efeito bioestimulante da solução contendo $30 \mathrm{~g} \mathrm{~L}^{-1}$ de extrato de alga e $100 \mathrm{~g} \mathrm{~L}^{-1}$ de $\mathrm{Ca}^{+2}$, e da solução contendo $15 \mathrm{~g}$ $\mathrm{L}^{-1}$ de ácido L-glutâmico associado a $15 \mathrm{~g} \mathrm{~L}^{-1}$ de extrato de alga e $100 \mathrm{~g} \mathrm{~L}^{-1}$ de $\mathrm{Ca}^{+2}$.

Cecato e Moreira (2013) verificaram que o extrato de alga aplicado via foliar em alface promoveu o maior acúmulo de massa seca e fresca, comprovando que este produto pode estimular os processos fisiológicos das plantas, dentre eles a fotossíntese.

Na cultura do cafeeiro, a aplicação foliar de extrato de algas proporcionou a melhoria na qualidade de bebida e um incremento de até $70 \%$ na produtividade. Além disso, auxiliou no controle de doenças, como ferrugem e cercóspora (FERNANDES; SILVA, 2011).

Os efeitos benéficos da aplicação do extrato de algas já foram comprovados em diversas culturas, no entanto, estudos sobre os benefícios da aplicação desse produto na cultura da batata são muito escassos. Portanto, com este trabalho objetivou-se avaliar o efeito de aplicações foliares do extrato de Ascophyllum nodosum no desenvolvimento e produtividade da cultura da batata.

\section{Material e Métodos}

O experimento foi realizado no período de abril a julho de 2008, conduzido dentro de uma área de plantio comercial de batata no município de Itapetininga-SP. O município encontra-se a $23^{\circ} 35^{\prime}$ de Latitude Sul e $48^{\circ} 02^{\prime}$ de Longitude Oeste de Greenwich, com altitude média de $670 \mathrm{~m}$ e clima Cfa, segundo a classificação de Köppen.

O solo da área experimental foi classificado como Latossolo Vermelho distrófico, conforme nomenclatura do Sistema Brasileiro de Classificação de Solos (EMBRAPA, 2006), com as seguintes características na camada de 0-0,2m: $\mathrm{pH}\left(\mathrm{CaCl}_{2}\right)=5,2 ; \mathrm{H}+\mathrm{Al}=36 \mathrm{mmol}_{\mathrm{c}}$ $\mathrm{dm}^{-3} ; \mathrm{Ca}^{2+}=42 \mathrm{mmol}_{\mathrm{c}} \mathrm{dm}^{-3} ; \mathrm{Mg}^{2+}=14 \mathrm{mmol}_{\mathrm{c}} \mathrm{dm}^{-3} ; \mathrm{K}^{+}=$ $3,3 \mathrm{mmol}_{\mathrm{c}} \mathrm{dm}^{-3} ; \mathrm{P}_{\mathrm{resina}}=56 \mathrm{mg} \mathrm{dm}^{-3} ; \mathrm{V} \%=62$ e $\mathrm{CTC}=$ $96 \mathrm{mmol}_{\mathrm{c}} \mathrm{dm}^{-3}$. Utilizou-se a variedade Asterix, semitardia, de pele vermelha, rendimento bastante elevado com tubérculos numerosos e ovais-alongados, olhos superficiais e polpa amarela.

O plantio da batata foi realizado mecanicamente em 02 de abril de 2008, utilizando-se tubérculos semente tipo II com brotação entre 0,4 e 0,6 cm e peso médio de 65g. A adubação de plantio constou da adição de 1.445 $\mathrm{kg} \mathrm{ha}^{-1}$ da fórmula 8-24-11, em mistura de grânulos.

Aos 20 dias após o plantio (DAP) realizou-se a aplicação da adubação de cobertura com $125 \mathrm{~kg} \mathrm{ha}^{-1}$ da fórmula 46-0-0 e posteriormente o procedimento de amontôa.

$\mathrm{Na}$ área experimental fez-se suplementação hídrica por aspersão do tipo convencional, visando suprir as necessidades do sistema solo-planta, principalmente nos períodos compreendidos entre o plantio e a emergência e do início da tuberização até a senescência das plantas. Assim durante todo o ciclo da cultura foi aplicada uma lâmina total de $180 \mathrm{~mm}$ de água. O controle de plantas daninhas, pragas e doenças foi realizado quimicamente num total de 16 aplicações, entre herbicidas, inseticidas, bactericidas e fungicidas, durante o ciclo da cultura.

O delineamento experimental utilizado foi o de blocos ao acaso, com cinco tratamentos e cinco repetições. Os tratamentos foram constituídos de cinco doses de extrato de alga Ascophyllun nodosum (produto comercial Acadian ${ }^{\circledR}$ ), $0 ; 0,5 ; 1 ; 2$; e $4 \mathrm{~L} \mathrm{ha}^{-1}$, aplicados às plantas via foliar.

As parcelas experimentais constaram de 5 linhas de plantio com $11,0 \mathrm{~m}$ de comprimento, espaçadas a 0,80 $\mathrm{m}$. O espaçamento entre plantas utilizado foi de $0,30 \mathrm{~m}$, totalizando aproximadamente 41.667 plantas por hectare. Para a aplicação via foliar do extrato de algas, utilizou-se pulverizador pressurizado com $\mathrm{CO}_{2}$, com pressão constante e volume de calda de $600 \mathrm{~L} \mathrm{ha}^{-1}$. As doses foram parceladas e aplicadas aos 23, 38 e 53 DAP. 
Durante o ciclo da cultura foram avaliados: altura de plantas medida em centímetros do colo da planta até o tufo apical; número de hastes por planta; intensidade de coloração verde da folha (ICV) determinada na quarta folha da batata utilizando-se o medidor portátil Chlorophyll Meter, modelo SPAD-5022; concentração de nutrientes na lâmina foliar de acordo com metodologia de Malavolta et al. (1997); área foliar da quarta folha usando o aparelho LI-COR que estima a área pelo princípio de células de grade de área conhecida (Li-cor 3100, 1996).

As avaliações altura de plantas, número de hastes por planta, ICV e concentração de nutrientes foliares foram efetuadas a cada quinze dias, aos 38, 53 e 68 DAP. A área foliar foi obtida somente aos 68 DAP. Estas determinações foram realizadas em dez plantas representativas na área útil de cada parcela experimental.

Aos 120 DAP, dez dias após a seca total das hastes, foram colhidas 15 plantas sequencialmente por parcela. Os tubérculos contidos em cada parcela foram contados, determinando-se o número de tubérculos por planta. Posteriormente foram colocados em sacos identificados e conduzidos até galpão onde foram escovados e lavados para a retirada do excesso de solo aderido. Após a retirada do excesso de solo aderido, os tubérculos foram pesados, sendo obtida a produtividade total. A partir da produtividade total foi feita a classificação de tubérculos pelo maior diâmetro transversal sendo dividida nas seguintes classes: classe I - tubérculos com diâmetro superior a $70 \mathrm{~mm}$; classe II.1 - tubérculos com diâmetro de 50 a $70 \mathrm{~mm}$; classe II.2 - tubérculos com diâmetro de 42 a $50 \mathrm{~mm}$; classe III - tubérculos com diâmetro de 33 a $42 \mathrm{~mm}$; e classe IV - tubérculos com diâmetro de 33 a $28 \mathrm{~mm}$.

Os dados foram submetidos ao teste $\mathrm{F}$, posteriormente as variáveis com efeito significativo foram ajustadas a um modelo de regressão com significância mínima de $5 \%$ pelo teste $\mathrm{t}$ para os parâmetros da equação. As análises foram realizadas com auxílio do programa computacional Sistema para Análise de Variância - SISVAR (FERREIRA, 2003).

\section{Resultados e Discussão}

O número de hastes por planta e a intensidade de coloração verde da folha de batata não foram influenciados pela aplicação do extrato de alga em nenhuma das avaliações realizadas. Aos 53 e 68 DAP, quando as plantas já haviam recebido dois terços e o total das doses, respectivamente, houve efeito positivo para a altura de plantas.

A altura de plantas ajustou-se de forma quadrática às doses aplicadas e segundo as equações; as doses de 3,6 e 3,1 $\mathrm{L} \mathrm{ha}^{-1}$ do extrato proporcionaram a máxima altura de plantas aos 53 e 68 DAP, respectivamente (Figura 1). $\mathrm{O}$ extrato de alga estimulou o crescimento vegetal das plantas, como também observado por Silva et al. (2010) que constataram o aumento da altura de mudas de crisântemo em vasos com a aplicação de extrato de alga.

A área foliar ajustou-se linearmente às doses de extrato de algas, atingindo $263 \mathrm{~cm}^{2}$ quando aplicada a dose de $4 \mathrm{~L} \mathrm{ha}^{-1}$ (Figura 2). Esse aumento se justifica, levando em conta que o extrato de alga é uma fonte de citocininas (FERNANDES; SILVA, 2011), classe de hormônios vegetais que entre suas propriedades promovem a divisão celular, com efeito sobre a expansão foliar e partição de assimilados das plantas (TAIZ; ZEIGER, 2013). A área foliar está relacionada com à determinação ou estimativa da superfície fotossinteticamente ativa, fator decisivo para ganhos em produtividade.

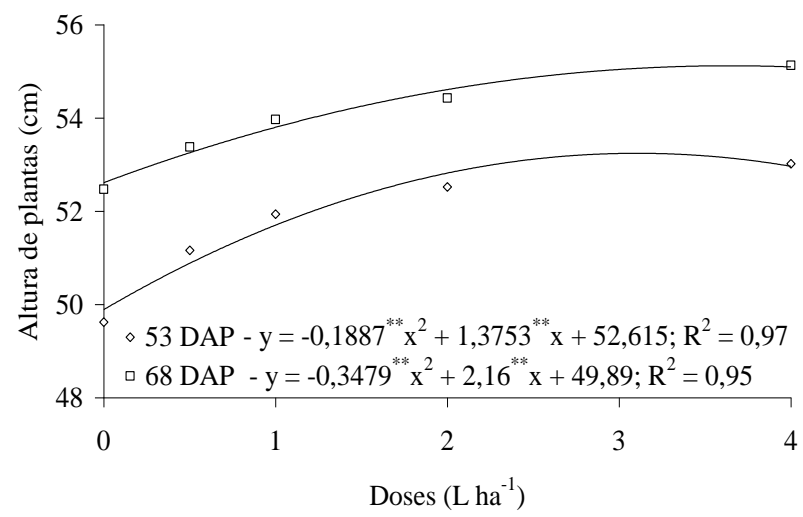

Figura 1. Altura de planta de batata (variedade Asterix) em função da aplicação foliar do extrato de alga Ascophyllum nodosum aos 53 e 38 DAP.

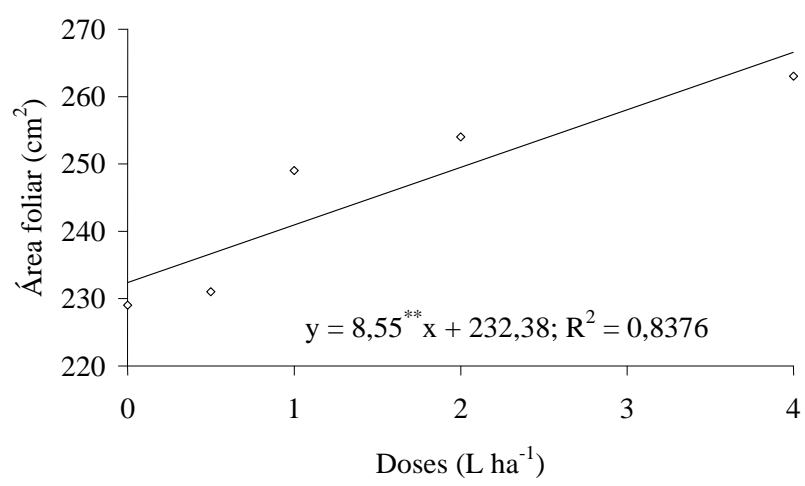

Figura 2. Área foliar da cultura da batata (variedade Asterix) em função da aplicação foliar do extrato de alga Ascophyllum nodosum.

Não foi verificado o efeito do extrato de algas no aumento do número de tubérculos por plantas. Porém houve aumento na produtividade total e comercial dos tubérculos (Figura 3). Obteve-se aumento de produtividade comercial de aproximadamente $6 \mathrm{t} \mathrm{ha}^{-1}$ em função da aplicação do produto, onde a dose de $4 \mathrm{~L}$ $\mathrm{ha}^{-1}$ proporcionou uma produtividade de tubérculos 
comerciais de $52 \mathrm{Mg} \mathrm{ha}^{-1}$. O incremento da produtividade deve-se à concentração considerável de auxinas, giberelinas e citocininas, presentes no extrato de alga, que estimulam o desenvolvimento das plantas de modo geral (FERNANDES; SILVA, 2011).

Neste experimento, como o número de tubérculos por planta não foi influenciado pelas doses, o aumento da produtividade pode ser justificado pela produção de tubérculos de maior diâmetro. Com o aumento das doses do extrato de alga, houve produção de tubérculos na classe I nas doses de 1,2 e $4 \mathrm{~L} \mathrm{ha}^{-1}$ e aumento dos tubérculos na classe II.1. (Figura 4). Verifica-se também a redução dos tubérculos nas classes II.2 e III (menores) com o aumento das doses. A produção de tubérculos de tamanho superior pode estar relacionada com a concentração de citocininas no extrato de algas, pois Mello et al. (2008) relatam que as citocininas são consideradas substâncias estimulantes da tuberização.

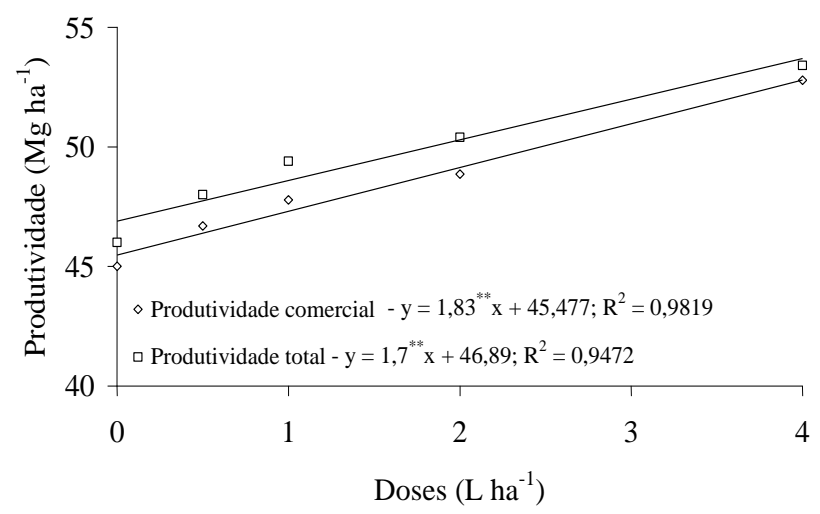

Figura 3. Produtividade total e comercial da batata em função em função da aplicação foliar do extrato de alga Ascophyllum nodosum.

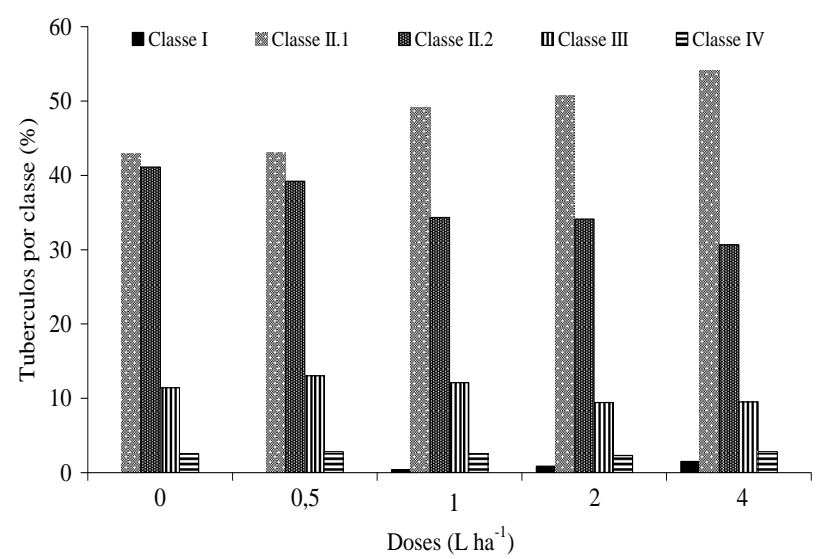

Figura 4. Porcentagem de tubérculos (com base no peso) nas diferentes classes em função da aplicação foliar do extrato de alga Ascophyllum nodosum.

O tamanho maior dos tubérculos não só contribui para a elevação da produtividade, mas também promoveu maior remuneração pelo produto. De acordo com Iuamoto (2014), na CEAGESP os maiores valores são pagos às batatas "Florão" (> $70 \mathrm{~mm})$ e "Especial" (42-70 mm) que compreendem as classes I (>70 mm), II. $1(50-70 \mathrm{~mm})$ e II.2 $(42-50 \mathrm{~mm})$ representadas neste estudo, obtidas em maior quantidade com a aplicação de extrato de alga.

\section{Conclusões}

As soluções contendo extrato de algas promoveram maior crescimento das plantas. A solução contendo $4 \mathrm{~L}$ $\mathrm{ha}^{-1}$ de extrato de alga proporcionou a produção de tubérculos de maior diâmetro e maior produtividade.

\section{Referências Bibliográficas}

CECATO, A.; MOREIRA, G. C. Aplicação de extrato de algas em alface. Cultivando o Saber, Cascavel-PR, v. 6, n. 2, p. 89-96, 2013.

EMBRAPA. EMPRESA BRASILEIRA DE PESQUISA AGROPECUÁRIA. Sistema Brasileiro de Classificação de Solos. 2. ed. Rio de Janeiro-RJ: Embrapa Solos, 2006. 306p.

FERNANDES, A. L.; SILVA, R. O. Avaliação do extrato de algas (Ascophyllum nodosum) no desenvolvimento vegetativo e produtivo do cafeeiro irrigado por gotejamento e cultivado em condições de cerrado. Enciclopédia Biosfera, GoiâniaGO, v. 7, n. 13, p. 147-157, 2011.

FERREIRA, D. F. Sisvar versão 4.2. Lavras-MG: DEX/UFLA, 2003. 1 CD-ROM.

IUAMOTO, M. Y. Comercialização de batata na CEAGESP. Batata Show, Itapetininga-SP, v. 5, n. 13, p. 34-35, 2005.

MALAVOLTA, E.; VITTI, G. C.; OLIVEIRA, S. A. Avaliação do estado nutricional das plantas: Princípios e aplicações. Piracicaba-SP: Potafos, 1997. 319 p.

MASNY, A.; BASAK, A.; ZURAWICZ, E. Effects of foliar application of KELPAK SL and GOEMAR BM 86 preparations on yield and fruit quality in two strawberry cultivars. Journal of Fruit and Ornamental Plant Research, Polônia, v. 12, p. 23-27, 2004.

MELLO, S. C.; SAKAMOTO, Y.; MELLO, V. D. C. Batata, In: CASTRO, P. R. C.; KLUGE, R. A.; SESTARI, I. Manual de fisiologia vegetal: fisiologia de cultivos. Piracicaba-SP: Agronômica Ceres, 2008, p. 47-57.

MÓGOR, A. F.; ONO, E. O.; RODRIGUES, J. D.; MOGOR, G. Aplicação foliar de extrato de alga, ácido L-glutâmico e cálcio em feijoeiro. Scientia Agraria, Curitiba-PR, v. 9, n. 4, p. 12-15, 2008.

SILVA, T. T. A.; PINHO, É. R. V.; CARDOSO, D. L. FERREIRA, C. A.; ALVIM, P. O.; COSTA, A. A. F. Qualidade fisiológica de sementes de milho na presença de bioestimulantes. Ciência e Agrotecnologia, Lavras-MG, v. 32, n. 3, p. 840-846, 2008. 
SILVA, C. P.; LASCHI, D.; ONO, E. O.; RODRIGUES, J. D.; MOGOR, A. F. Aplicação foliar do extrato de alga Ascophyllum nodosum e do ácido glutâmico no desenvovimento inicial de crisântemos (Dendranthema morifolium (Ramat.) Kitam.) em vasos. Revista Brasileira de
Horticultura Ornamental, Campinas-SP, v. 16, n. 2, p. 179$181,2010$.

TAIZ, L.; ZEIGER, E. Fisiologia vegetal. 5. ed. Porto AlegreRS: Artmed, 2013. 954 p. 